\title{
大分県におけるスクリーニングマンモグラフィの実態調査に基づいた 線量と画質との関係に関する検討
}

\author{
房常 朋視 ${ }^{1)}$ 藤原 伸行 ${ }^{2)}$ 甲斐 倫明 ${ }^{3)}$ 草間 朋子 ${ }^{3)}$ \\ 大分県地域保健支援センター1) \\ 大分赤十字病院2) \\ 大分県立看護科学大学 ${ }^{33}$
}

\begin{abstract}
大分県におけるスクリーニングマンモグラフィの調査を行ったところ，各施設における 実質的乳腺線量は，対象年龄や記録系の違いにより施設間で最大 4.25 倍の差があり，記録 系別に評価すると， F-S 系施設に扔ける線量平均は CR のそれに比べて約 2.4 倍の差があ った。ここで, 大分県に扔ける ACR156ファントムの平均濃度に扔ける基準線量を導入し, 基準線量と画質との関係を調査したところ，F-S 系では線量と画質にある程度の相関が認 められるものの, 画質が著しく上昇するまでの効果はなかった。また, CR (computed radiography)でもその傾向は認められなかった。

以上の結果，適正なスクリーニング検查を行うためには，施設毎に最適電圧を決定し， グリッドを使用の上, 中高感度増感紙を使用したコンベンショナルシステムによる撮影が 良好な結果をもたらすことを確認した。
\end{abstract}

Key words：スクリーニングマンモグラフィ, 各施設における実質的乳腺線量, F-S 系, CR

\section{はじめに}

近年，わが国における女性の乳癌罹患率の増加 に伴い, 旧厚生省は, 従来の視触診のみの乳癌検 診システムを見直し，平成12年 4 月 1 日から「が ん予防重点健康教育及びがん検診実施のための指 針」を改正し，50歳以上の隔年にマンモグラフィ を併用実施することを決定した。この決定の背景 には，適切な精度管理によって，画質と被曝線量 を適正化することにより，集団検診としての有効 性が確立できるとした実態調査 ${ }^{1}$ が役割を果たし ていると考えられる。

画質の評価は, American College of Radiology

別冊請求先：干870-0011 大分市大字駄原2892-1 大分県地域保健支援センター 房常朋視 E-mail address:wfusa@d5.dion.ne.jp
(ACR)のマニュアル2゙では，RMI156ファントムを 用いて繊維・石灰・腫瘤の各モジュールにおける 基準評価点数方式が乳癌検診システムのガイドラ イン ${ }^{3)}$ に採用され，マンモグラフィによる乳がん 検診の精度管理マニュアル () (以下，マニュアル) にも継承されており，その再現性と評価のバラッ キに多少問題を残すことを除けば，比較的容易に 評価が可能である。一方, 乳腺線量については IAEA (International Atomic Energy Agency)が, $3 \mathrm{mGy}$ 以下 $(\mathrm{Grid}+)$ とするガイダンスレベルを 勧告5) し(以下，ガイダンスレベル)，わが国にお いてもマニュアルで最大 $3 \mathrm{mGy}(2 \mathrm{mGy}$ 以下が 望ましい)とすることが明記されている6 ${ }^{6}$ 。その方 法はRMI156ファントムにおける基準化された 「平均乳腺線量」として評価することとなってい るが, 各施設における読影濃度の好みや対象年 齢，撮影機材や条件および近年隆盛をきわめる 
$\mathrm{CR}$ (computed radiography)等のデジタルシステ 公の普及を考慮すると，その結果は実質的な線量 と乘離していることも考えられる。

本研究では, 大分県に㧍けるスクリーニングマ ンモグラフィ(以下, SMG)の実態調査を行い, 各施設における実質的な乳腺線量の測定，および 156 ファントムを用いた大分県下の平均的な写真 濃度における線量 (以下，156ファントム線量)と その濃度における画質の関係についての検討を試 みたので結果を報告する。

\section{1. 方 法}

\section{1) 実態調查方法}

大分県下 42 の医療施設に対し, (1)SMG 実施の 有無, (2)装置の性能, (3)記録系および現像条件, (4)平均的乳房条件における管電圧, に関する調査 を行った(平成11年 1 月〜 3 月)。

\section{2)実質的乳腺線量評価}

各施設における標準乳房の条件(压迫厚・電压 ・ mAs)に扮ける照射線量 (ESE)を圧迫厚に合致 させた発泡スチロールを置き, その上にチェンバ を固定して，照射野中心においてそれぞれ 5 回測 定した平均值をもとに次式を用いて算出した。

\section{$\mathrm{Dg}=\mathrm{DgN} \times \mathrm{ESE}$}

$\mathrm{Dg}$ : 乳腺線量 $(\mathrm{mGy})$

ここで, DgN：変換係数(WT Sobl らによる average glandular dose table ${ }^{7)}$ 利用), ESE : 皮 虐照射線量, である。但し, 乳腺/脂肪比は 1.0 と いう前提で算出した(図 1)。

なお，DgNの決定に必要な HVLは，B 施設に
おいてビクトリン $6000 \mathrm{M}$ NERO アナライザーを 測定し， $0.35 \mathrm{mmAl}$ を代表值とした。

\section{3) 156 ファントム線量の測定}

全施設同一の RMI156ファントムを用いて各施 設の設定 AEC (auto exposure control) (全施設 $\mathrm{AEC}$ 使用)の条件で撮影した中心濃度平均は $\mathrm{D}=$ 1.2であり，ガイドラインより若干低かったが， より実態に即した評価を行うため, $\mathrm{D}=1.2 \pm 0.05$ の範囲内の濃度条件を基準に定め, 圧迫厚 $4 \mathrm{~cm}$ の位置(RMI 156ファントムの厚み)における照射 線量を 5 回測定し, 平均值から算出した。

線量測定には, キャピンテック192線量計 (PS 033シャローチェンバ使用)を使用した。

\section{4) 画質評価}

156ファントム線量に合致したファントム像を ガイドラインに準拠した方法で，技師 8 名，放射 線科医 1 名, 計 9 名による目視ブラインド評価を 行った。

なお，E施設においては，スクリーンをより高 感度のタイプに交換したものも評価の対象とし た。

\section{2. 結 果}

\section{1) SMG 実施状況}

SMG を実施している施設は 6 施設 (以下, A, B, $\mathrm{C}, \mathrm{D}, \mathrm{E}, \mathrm{F}, \mathrm{G}$ と呼ぶ) とした。各施設の年間受診 者数は最大 414 人, 最小 30 人平均 168.9 人であっ た。C施設は職域検診が多く，それ以外の施設は 住民検診もしくはドック形式の検診であった(図

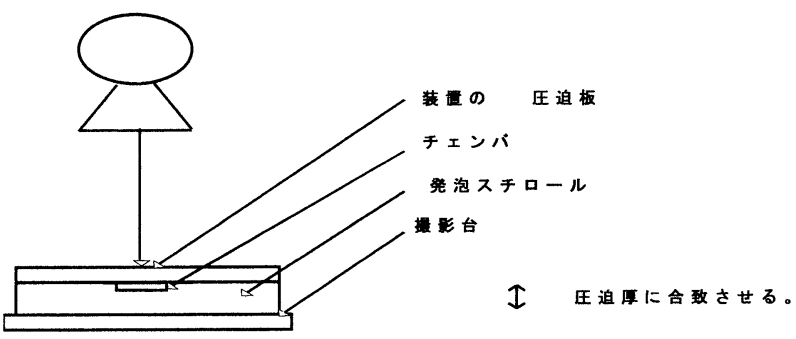

図 1. 線量測定概念図 


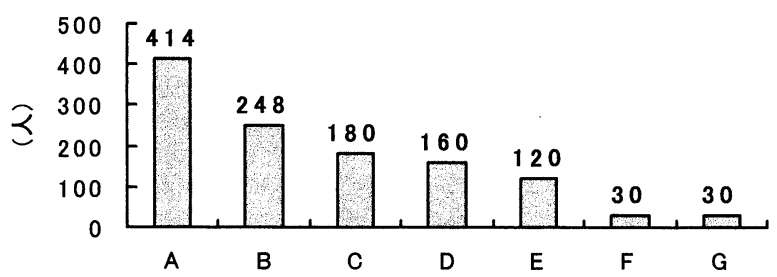

図 2. 施設別にみた $\mathrm{SMG}$ の年間受診者数

表 1. 各施設における機器

\begin{tabular}{c|c|c|c|c|c}
\hline 施設 & 装置名 & ターゲット & フィルター & 焦点 $\mathrm{mm} \times \mathrm{mm}$ & グリッド \\
\hline $\mathrm{A}$ & $\mathrm{GE}$ セノグラム $800 \mathrm{~T}$ & $\mathrm{Mo}$ & $\mathrm{Mo}, \mathrm{Rh}$ & $0.1 \times 0.3$ & 移動型 \\
$\mathrm{B}$ & sepio & $\mathrm{Mo}$ & $\mathrm{Mo}$ & $0.1 \times 0.3$ & 移動型 \\
$\mathrm{C}$ & $\mathrm{GE}$ セノグラム $\mathrm{DMR}$ & $\mathrm{Mo}, \mathrm{Rh}$ & $\mathrm{Mo}, \mathrm{Rh}, \mathrm{Al}$ & $0.1 \times 0.3$ & 移動型 \\
$\mathrm{D}$ & 日立 DMF- $51 \mathrm{Mb}$ & $\mathrm{Mo}$ & $\mathrm{Mo}$ & $0.2 \times 0.5$ & なし \\
$\mathrm{E}$ & $\mathrm{GE}$ セノグラム $\mathrm{DMR}$ & $\mathrm{Mo}, \mathrm{Rh}$ & $\mathrm{Mo}, \mathrm{Rh}, \mathrm{Al}$ & $0.1 \times 0.3$ & 移動型 \\
$\mathrm{F}$ & 東芝 $\mathrm{MGU}-10 \mathrm{c}$ & $\mathrm{Mo}$ & $\mathrm{Mo}$ & $0.15 \times 0.4$ & 移動型 \\
$\mathrm{G}$ & アコマ $\mathrm{ESP} 200$ & $\mathrm{Mo}$ & $\mathrm{Mo}$ & $0.1 \times 0.3$ & 移動型 \\
\hline
\end{tabular}

表 2. 各施設に扔ける記録系

\begin{tabular}{|c|c|c|c|}
\hline 施設 & スクリーン・CR 装置 & フィルムまたは IP & 条件, 階調 \\
\hline A & Fuji MAMMOFINE & Fuji UM-MA HC & $33^{\circ} \mathrm{C} \quad 90$ 秒 \\
\hline B & コダック MinR-Med & MinR 2000 & $34^{\circ} \mathrm{C} \quad 120$ 秒 \\
\hline $\mathrm{C}$ & コダック Min 2000 & MinR 2000 & $35^{\circ} \mathrm{C} \quad 90$ 秒 \\
\hline $\mathrm{D}$ 新 & FCR 7000 & $\mathrm{HR}-3$ & R（S 145） \\
\hline D 旧 & FCR 7000 & $\mathrm{HR}-3$ & $\mathrm{R}$ (S 230) \\
\hline $\mathrm{E}$ & FCR AC- 3 & HRV & O (S 150) \\
\hline $\mathrm{E}$ & コダック MinR & MinR 2000 & $35^{\circ} \mathrm{C} \quad 60$ 秒 \\
\hline F & FCR 5000 & HRV & $\mathrm{R}$ (S 100) \\
\hline G & コダック MinR & MinR & $34^{\circ} \mathrm{C} \quad 28$ 秒 \\
\hline
\end{tabular}

2)。

\section{2)装 置}

全施設で Mo フィル夕装備となっており, A, C, $\mathrm{E}$ の施設では Rh フィルタも選択可能となってい る。なお,グリッド未装備が 1 施設存在した(表 1)。

\section{3) 記録系}

$\mathrm{CR}$ が 3 施設で採用されており，Eの施設では $\mathrm{CR}$ と $\mathrm{F}-\mathrm{S}$ 系の使い分けを行っている。 $\mathrm{CR}$ 装置
の $\mathrm{S}$ 值は約100〜150の範囲であった。フィルム の感度は約150～200前後のものが使用されている が，スクリーンは低感度から中高感度まで多彩で あった (表 $\left.2,3^{8)}\right)$ 。

\section{4) 各施設の平均的条件における管電圧}

$27 \mathrm{kV}$ が71\%を占めており, 平均は $27.3 \mathrm{kV} て ゙$ あった。C 施設の電圧が高いのは, 乳腺含有率の 高い若年被検者が多い職場検診に由来しているこ とが考えられる(図3)。 
表 3. 各種増感紙フィルムの組合せにおける相対感度

\begin{tabular}{c|l|c|c}
\hline メーカー & \multicolumn{1}{|c|}{ 増感紙 } & フィルム & 相対感度 \\
\hline \multirow{2}{*}{ Kodak } & MinR & MinR & 100 \\
& MinR Medium & MinR & 169 \\
& MinR 2000 & MinR 2000 & 200 \\
\multirow{2}{*}{ Fuji } & HR Mammo Fine & UM-MAHC & 173 \\
& HR Mammo Medium(参考) & UM-MAHC & 231 \\
Konica & MD-100 & CM-H & 169 \\
(参考) & MM-150 & CM-H & 258 \\
& MH-200 & CM-H & 360 \\
\hline
\end{tabular}

(出典：平成11年度厚生労働省老人保健事業推進費等補助金 マンモグラフィによる乳がん検診 の精度管理マニュアル)

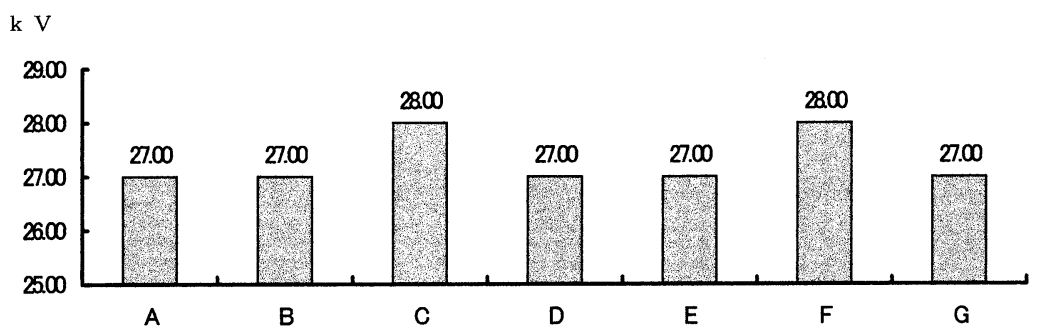

図 3. 各施設における標準乳房撮影管電圧

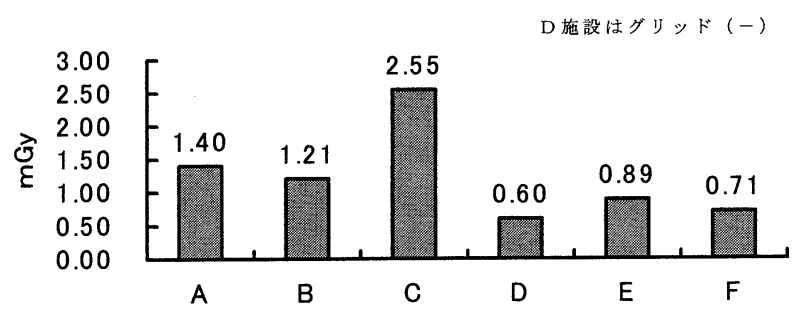

図 4. 施設別実質的乳腺線量

\section{5)実質的乳腺線量}

実質的乳腺線量は $0.60 \sim 2.55 \mathrm{mGy}$ の範囲(最 高/最低比は約4.25)で，平均は1.23 mGy であ り，記録系別に評価すると， $\mathrm{F}-\mathrm{S}$ 系の線量平均は $\mathrm{CR}$ の平均に比べて約2.4倍であった。 $(\mathrm{G}$ 施設の 測定はできなかった。)なお，施設申告による乳房 圧迫厚の平均は約 $3.6 \mathrm{~cm}$ であった（図 4)。

\section{6) 画質評価}

管電圧 $27 \mathrm{kV}$ および $28 \mathrm{kV}$ における156ファント ム線量と対比させて, 施設別の散布図を箱ライン
図として作成した(図 5〜 10)。

各グラフの縦軸は評価ポイント数を, 横軸は 156 ファントム線量をあらわし, ラインの範囲が評価 の最大一最小值を意味し, 箱の範囲が標準誤差 を, 箱内ラインが平均值である。グラフ中の $\mathrm{E}$ 低とは $\mathrm{E}$ 施設の標準スクリーン $(\mathrm{MinR})$ であり, E 高とはスクリーンに MINR Med を使用したも のである。 D 施設の条件が $27 \mathrm{kV}$ 固定であったた め, $28 \mathrm{kV}$ の測定は行っていない。また D 施設に おいて, $\mathrm{S} / \mathrm{N}$ 比向上を考慮し, 線量を約 2 倍に 設定した撮影を実験的に取り入れ，それぞれD 


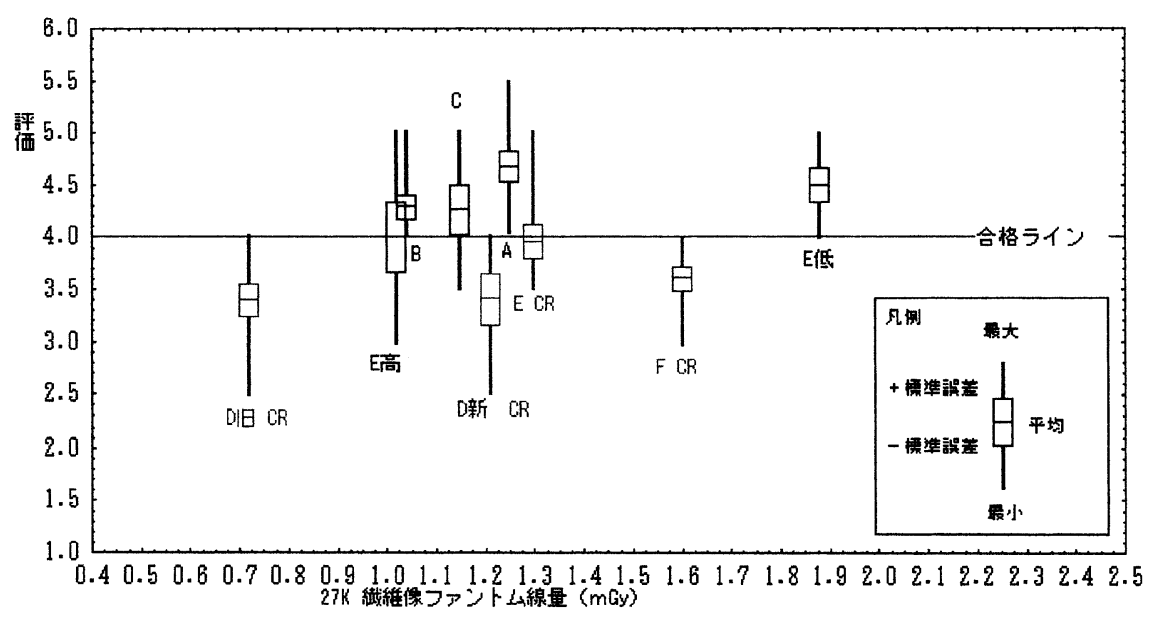

図 5

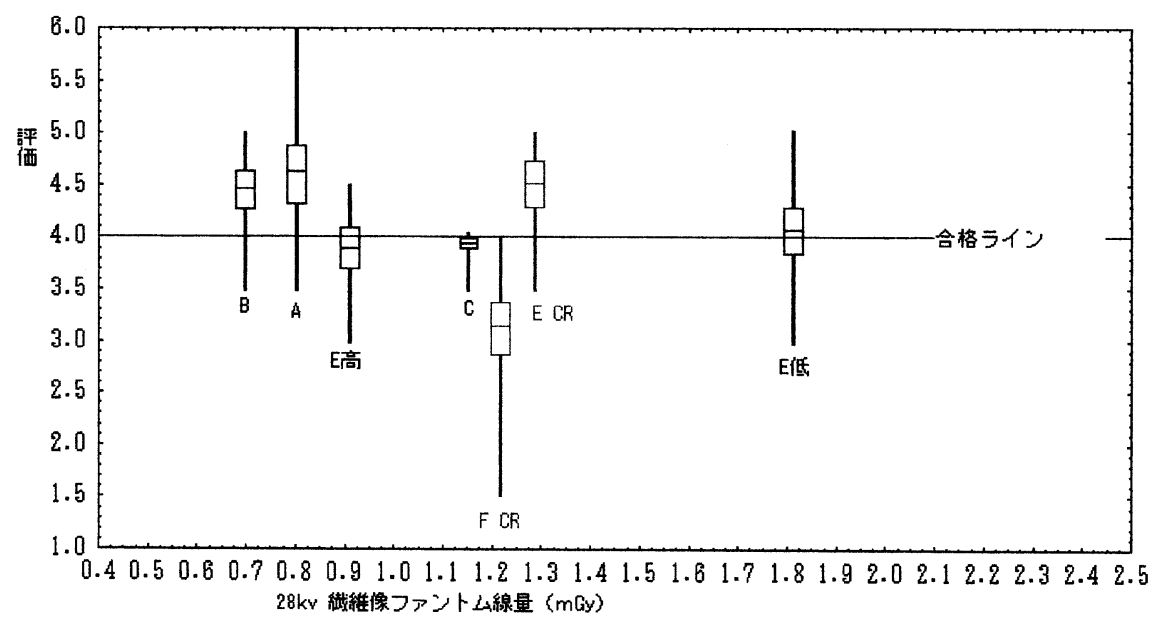

図 6

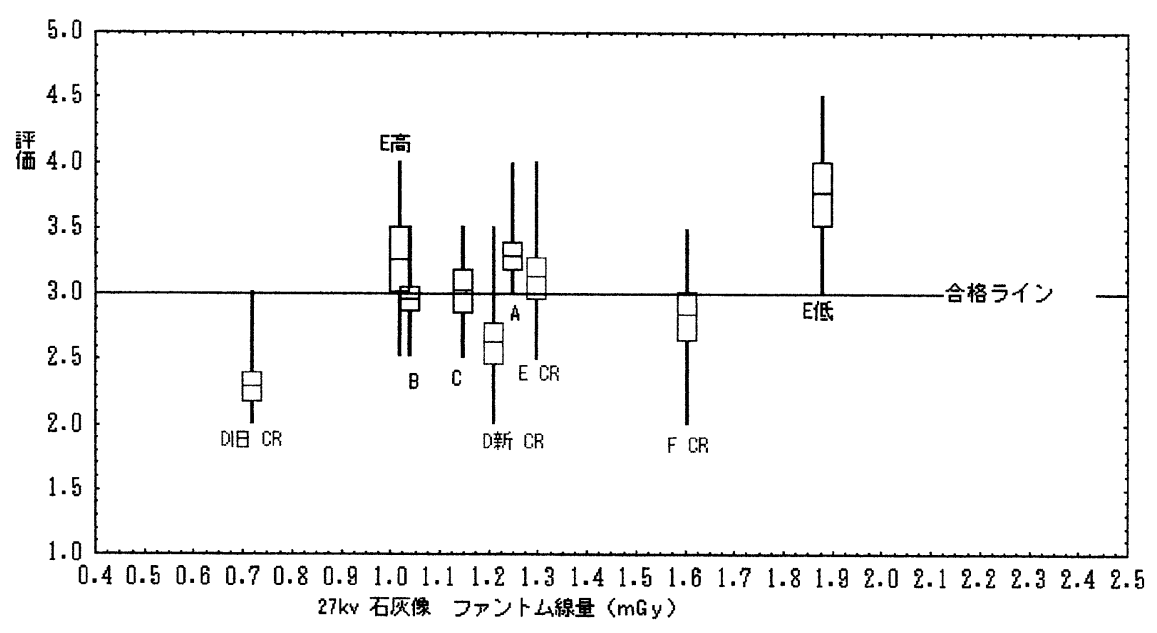

図 7 


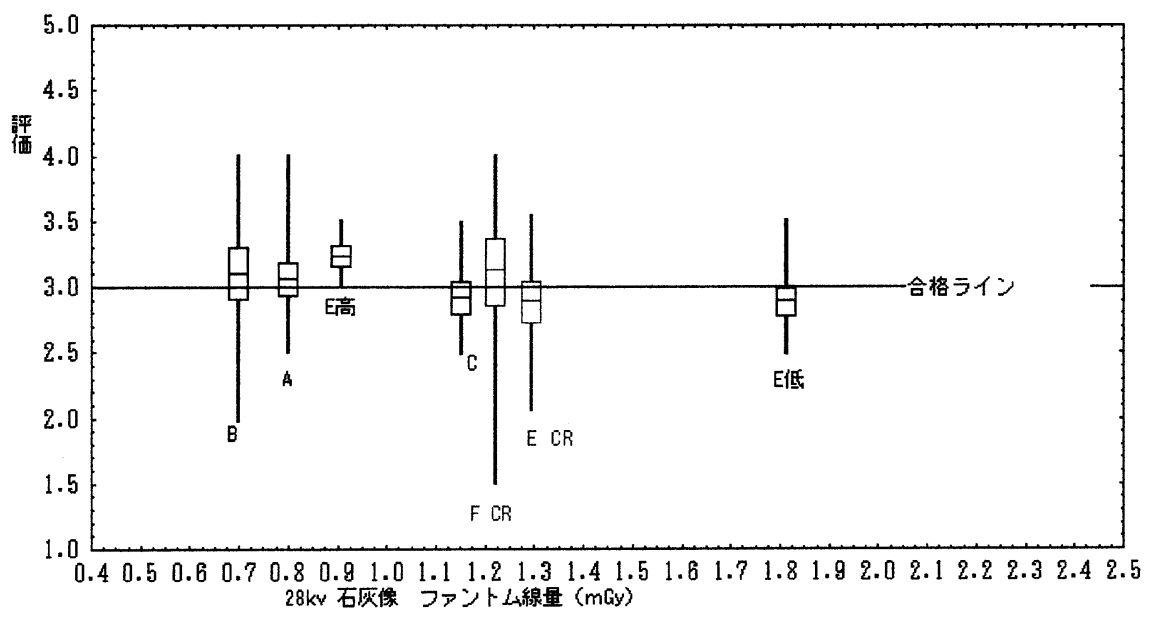

図 8

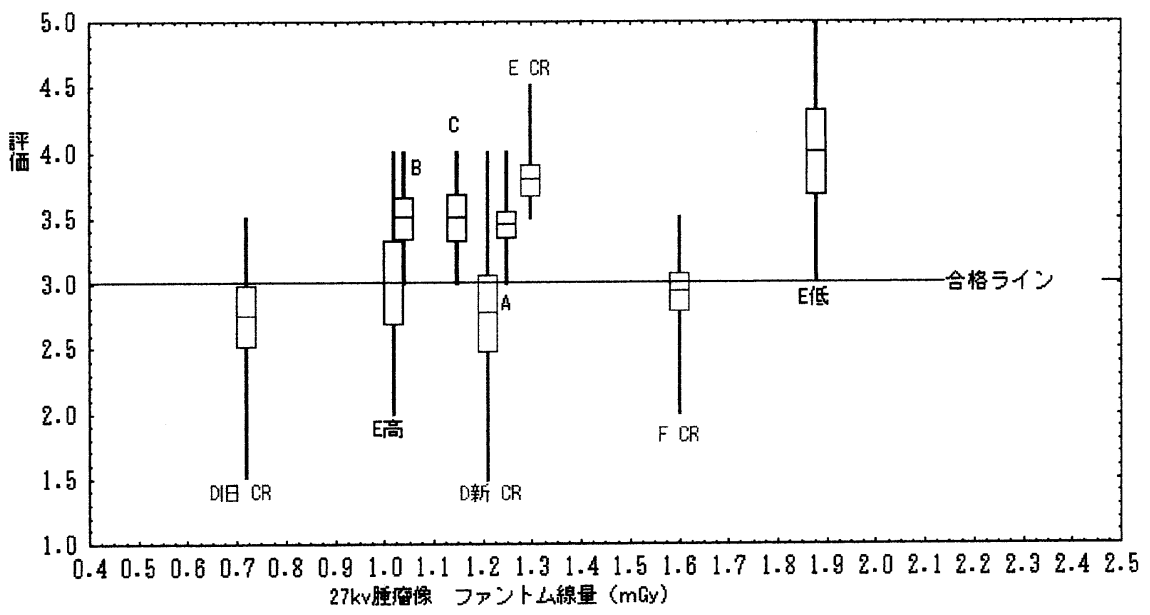

図 9

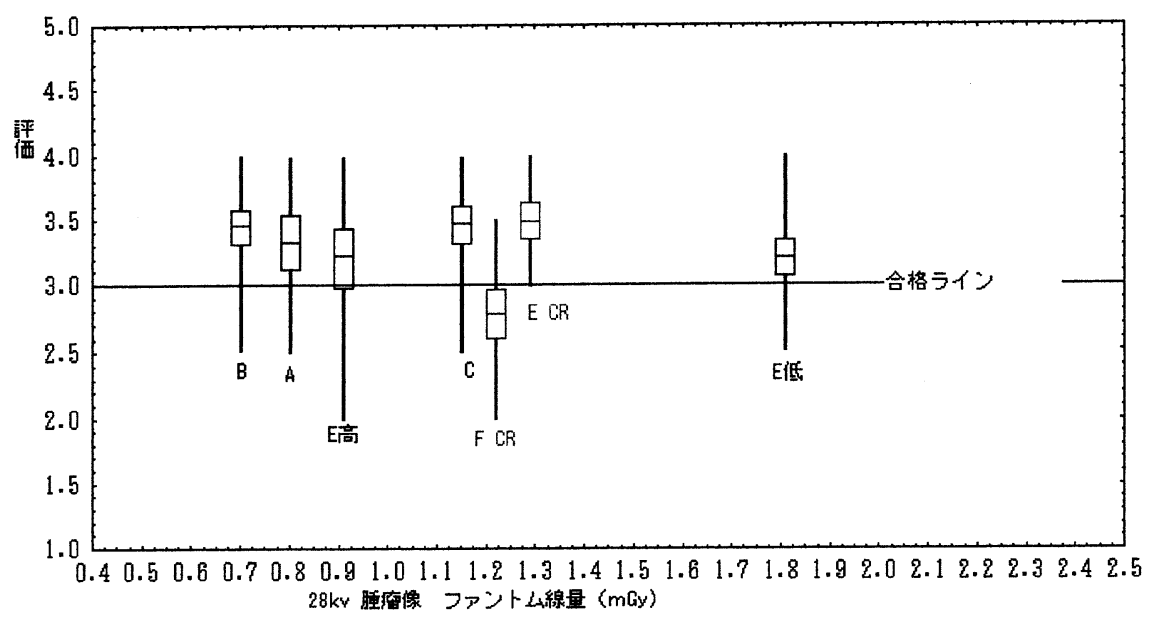

図 10

日乳癌検診学会誌(J.Jpn.Assoc.Breast Cancer Screen.) 2002, 11(3) OCT ： 275 


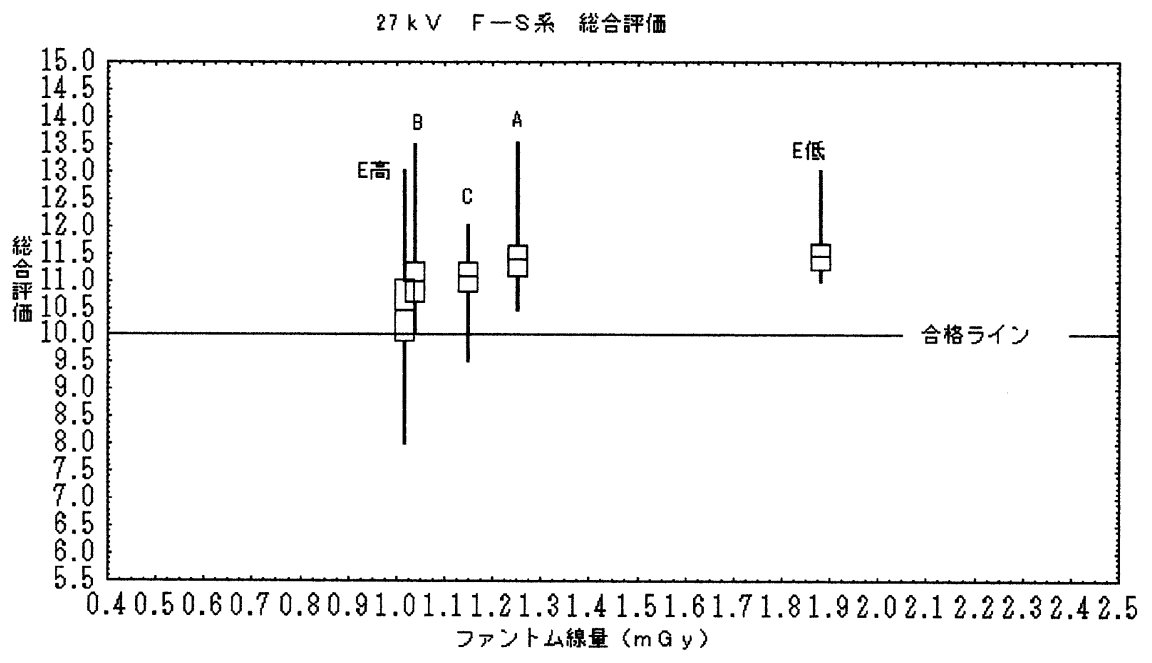

図 11

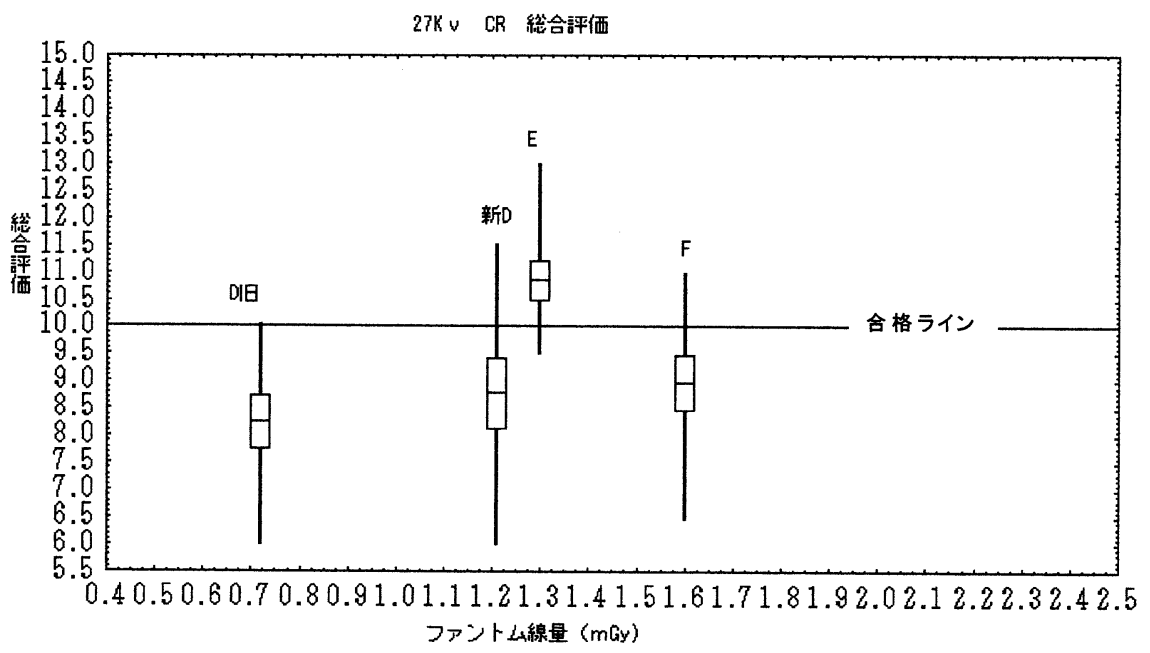

図 12

旧，D 新と表記した。

\section{(1)絾維像}

$\mathrm{F}-\mathrm{S}$ 系では B 施設を除いて， $28 \mathrm{kV}$ の平均評価 が低下したが，CRでは E 施設で向上していた（図 $5,8)$ 。

\section{(2)石灰像}

纎維像と同様の傾向であったが，特に $\mathrm{E}$ 施設 の低感度 F-S 系での $28 \mathrm{kV}$ における低下が目立 つ。逆に $\mathrm{CR}$ では $\mathrm{E}, \mathrm{F}$ の両施設で評価が向上し, 特に $\mathrm{E}$ 施設の $\mathrm{CR}$ は平均評価では最高得点であっ た(図 6,9)。

\section{(3)腫瘤像}

$\mathrm{F}-\mathrm{S}$ 系では $\mathrm{E}$ 施設の高感度を除き， $28 \mathrm{kV}$ の方 が平均評価が下がった。 $\mathrm{E}$ 施設の低感度 $\mathrm{F}-\mathrm{S}$ 系 での $28 \mathrm{kV}$ における低下が目立つ。CRでは $27 \mathrm{kV}$ で $\mathrm{E}$ 施設が良好な平均的評価を得た(図 7,10)。

(4)全体的評価

各施設の総合評価を前述同様の散布図で示す （図 11〜 14）。記録計別に見ると，F-S系が CR 系を凌駕しているように思われる。

$\mathrm{E}$ 施設の $\mathrm{F}-\mathrm{S}$ 系低感度スクリーンでは， $27 \mathrm{kV}$ における石灰像と腫瘤像で良い結果をもたらして 


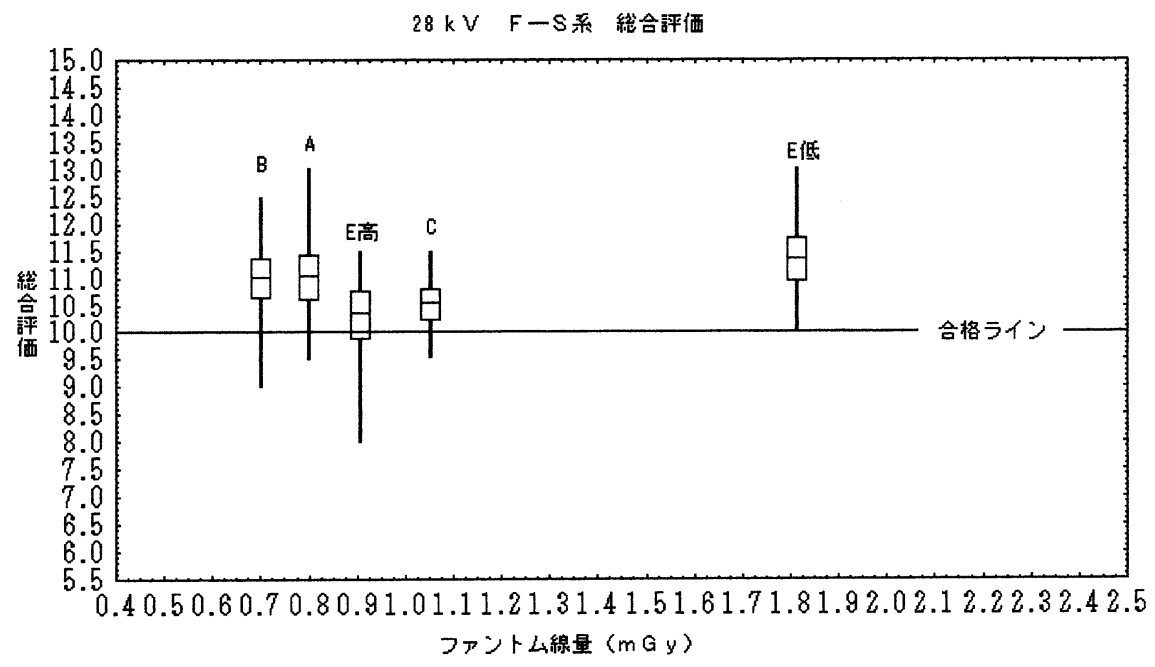

図 13

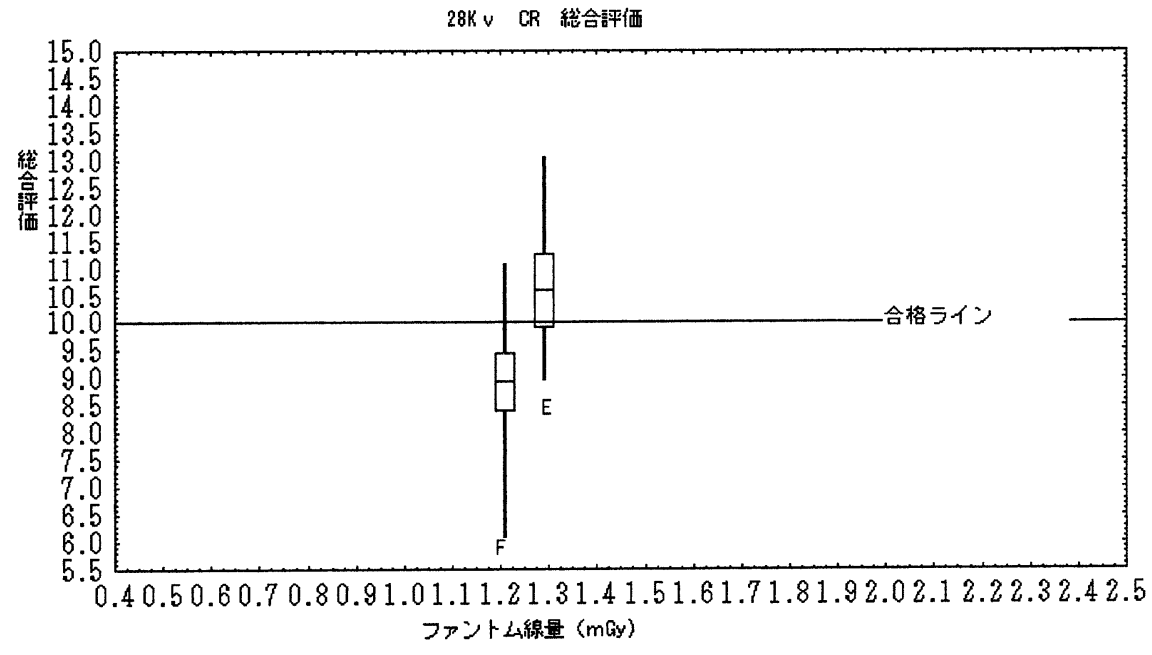

図 14

いる反面， $28 \mathrm{kV}$ では評価が低下した。また，同 施設での高感度スクリーンでは全体的に評価が低 かった。

\section{7) 156 ファントム線量と画質の関係}

$27 \mathrm{kV}$ における F-S 系では線量と画質が正の相 関傾向があるように思われるが $(\mathrm{R}=0.96)$, 評価 が著しく増すほどの効果はなく，むしろ使用管電 圧でバラツキが大きかった。

また，D施設 (CR) は全体的に評価が低かった。 ために， $\mathrm{S} / \mathrm{N}$ 比を上昇させることにより，評価
を改善する策として，線量を約1.7倍付加して撮 影したが，総合評価では有意な変化は見られなか った(図 11〜 14)。

\section{3. 考 察}

各施設の実質的乳腺線量のバラツキが大きい原 因は，記録系や対象被検者の相違のみならず，読 影医の写真濃度の好みも関係していると思われ る。

$\mathrm{E}$ 施設の高感度スクリーンは全体的に画質評価 が低いのは，短時間現像によるコントラストの低 
表 4. 各施設別ファントム線量 - 総合評価 (単位: 線量 $=m G y$, 率 $=\%$ )

\begin{tabular}{|c|c|c|c|c|c|c|}
\hline 施設 & $\begin{array}{c}27 \mathrm{kV} \text { 線量 } \\
\text { (a) }\end{array}$ & $\begin{array}{c}27 \mathrm{kV} \text { 評価 } \\
\text { (b) }\end{array}$ & $\begin{array}{c}28 \mathrm{kV} \text { 線量 } \\
\text { (c) }\end{array}$ & $\begin{array}{c}28 \mathrm{kV} \text { 評価 } \\
\text { (d) }\end{array}$ & $\begin{array}{c}\text { 線量低下率 } \\
(\mathrm{c} / \mathrm{a} * 100)\end{array}$ & $\begin{array}{c}\text { 評価低下率 } \\
(\mathrm{d} / \mathrm{b} * 100)\end{array}$ \\
\hline A & 1.25 & 11.44 & 0.80 & 11.10 & 64.0 & 97.0 \\
\hline B & 1.04 & 10.94 & 0.70 & 11.00 & 67.3 & 100.5 \\
\hline $\mathrm{C}$ & 1.15 & 11.06 & 1.05 & 10.51 & 91.3 & 95.0 \\
\hline $\mathrm{E}$ 高感度 & 1.02 & 10.44 & 0.91 & 10.33 & 89.2 & 98.9 \\
\hline $\mathrm{E}$ 低感度 & 1.88 & 11.51 & 1.81 & 11.33 & 96.3 & 98.4 \\
\hline $\mathrm{D}(\mathrm{CR})$ 旧 & 0.72 & 8.22 & 未測定 & 未測定 & 不明 & 不明 \\
\hline $\mathrm{D}(\mathrm{CR})$ 新 & 1.21 & 8.78 & 未測定 & 未測定 & 不明 & 不明 \\
\hline $\mathrm{E}(\mathrm{CR})$ & 1.30 & 10.89 & 1.29 & 10.61 & 99.2 & 97.4 \\
\hline $\mathrm{F}(\mathrm{CR})$ & 1.60 & 9.00 & 1.22 & 8.83 & 76.3 & 98.1 \\
\hline $\mathrm{F}-\mathrm{S}$ 平均 & 1.27 & 11.08 & 1.05 & 10.85 & 83.1 & 98.0 \\
\hline グリット $(+) C R$ 平匀 & 1.45 & 9.95 & 1.26 & 9.72 & 86.9 & 97.7 \\
\hline 全 CR 平均 & 1.21 & 9.22 & 1.26 & 9.72 & 103.9 & 105.4 \\
\hline 全平均 & 1.24 & 10.25 & 1.11 & 10.53 & 89.6 & 102.7 \\
\hline
\end{tabular}

評価は平均を示す。

下が関与しているものと思われる。反面，現像時 間が90秒の施設 $(\mathrm{A}, \mathrm{C}$ 施設)では評価にそのよう な問題はなく,「片面乳剤フィルムは現像条件の 影響を受けやすく, 現像温度 $34^{\circ} \mathrm{C}$, 現像処理時間 が90秒から110秒のとき，かぶり濃度の上昇を伴 うことなく最適なコントラストを呈し, 高コント ラストフィルムでは長時間現像処理を行わなくて も最適なコントラストと感度が得られた。とす る朝原正喜らの報告9) と矛盾しないと思われた。

スクリーンの種類では，一般的に低感度スクリ ーンは粒状性が良く画質が良いとされるが，画質 にバラツキが大きく, 被曝線量増加のリスクも無

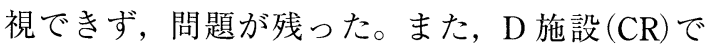
は線量を増加してシグナルレベルの改善を計った にもかかわらず画質評価が全体的に低いのは，グ リッド未使用による散乱線ノイズの影響によるも のと思われる。

電圧と画質を比較すると, 一般的には電圧が上 昇するとコントラストが落ち, 評価の低下につな がると思われがちである。しかし，B 施設では28 $\mathrm{kV}$ の方が良好な総合評価を得ており, 画質低下 を来たさない範囲で最適な電压を施設毎に決定す る必要性が示唆された。

記録系と線量の関係について，グリッド $(+)$ の
みの施設について比較すると， $27 \mathrm{kV}$ では F-S 系 平均 $1.26 \mathrm{mGy}$ に対し $\mathrm{CR}$ 平均が $1.45 \mathrm{mGy}$ であ り, $28 \mathrm{kV}$ では F-S 系が平均 $1.05 \mathrm{mGy}$ に対し $\mathrm{CR}$ 平均が $1.27 \mathrm{mGy}$ であり, 各電圧ともに CRの線 量が高かった。マンモグラフィによる乳がん検診 適正実施のための研究101においても CRの平均線 量が $\mathrm{F}-\mathrm{S}$ 系より高いことが報告されている。

電圧が線量に及ぼす影響を検討したところ，電 圧の上昇に伴い156ファントム線量は, F-S 系で は最大で $64 \%$ に低下したが(A 施設)， CR では線 量低下がほとんどなく，デジタルシステムによる 画像構築には濃度補正を含む幾多のアルゴリズム が機能しているため, 直感的に把握し難い一面を のぞかせた (表4)

\section{まとめ}

本研究では，画質と線量の関係に注目して分析 した結果, 適正な SMGの撮影条件は以下の通り にまとめられる。

1 ) グリッドは必ず使用する。

2 ) 低感度スクリーンは電圧上昇にともない, 石灰化像や腫瘤像において評価が低下傾向にある ことに加えて, 線量が他の $\mathrm{F}-\mathrm{S}$ 系と比較して, $28 \mathrm{kV}$ においては最大で2.58倍であり, SMGへ 
の使用は避けるべきである。一方，高コントラス トフィルムと中高感度スクリーンを使用すると， 線量と画質の適正化が可能であり，電圧の変化に よるバラッキの少ない写真を得ることができると 思われる。

3 ) CR は SMG に使用するには, 画質と線量の 両面でパラメータを含めて今後さらに検討を要す る。

4 ) 高コントラストフィルムを使用するならば 現像時間は90秒でも問題はないと思われる。

5 )施設毎に，各管電圧における RMI156ファ ントムを用いた画質評価を行い，画質低下を来た さない範囲で可能な限り高い管電圧を決定し, AEC で得られた条件を補正することにより乳腺 線量を低減することが可能となる。

\section{謝 辞}

最後にこの調查にご協力頂きました山香町立国 保総合病院，東国東広域国保総合病院，大分岡病 院, 鶴友会こが病院, 社会保険南海病院, 大分日 赤病院の皆様に感謝いたします。

\section{【文 献】}

1) 大内憲明, 遠藤登喜子, 東田善治, 他：マンモ グラフィによる乳癌検診を実施するにあたって の実態調查 厚生省班研究報告. 日乳癌検診学 会誌, 8 : 15-22, 1999

2 ) American College of Radiology: Mammography Quality Control Manual. ACR, 1994
3) 日本乳癌検診学会ガイドライン作成委員会：マ ンモグラフィを導入した乳癌検診システムのガ イドライン. 篠原出版新社, 1997, p. 31

4 ）大内聴明編：平成11年度厚生労働省老人保健事 業推進費等補助金 マンモグラフィによる乳が ん検診の精度管理マニュアル. 東北大学大学院 医学系研究科, 2000, p. 32

5 ) International Atomic Energy Agency:International Basic Safety Standards for Radiation Protection against Ionizing Radiation and for Safety of Radiation Sources, Safety Series, 115-I, IAEA, 1994

6 ）大内憲明編：平成11年度厚生労働省老人保健事 業推進費等補助金 マンモグラフィによる乳が ん検診の精度管理マニュアル. 東北大学大学院 医学系研究科, 2000, p. 38

7 ) Sobl WT and Wu X: Parameterization of mammography normalized average glandular dose table. Med Phys, 24, 547-554, 1997

8 ）大内憲明編：平成11年度厚生労働省老人保健事 業推進費等補助金 マンモグラフィによる乳が 几検診の精度管理マニュアル. 東北大学大学院 医学系研究科, 2000, p. 16

9 ) 朝原正喜, 星川敦司, 東田善治, 他：乳房撮影 用フィルムにおける写真特性と現像条件に関す る実験的研究. 日乳癌検診学会誌, 9-2:237245,2000

10）大内憲明編：平成12年度厚生労働省老人保健事 業推進費等補助金 分担研究マンモグラフィに よる乳がん検診の適正実施のための研究報告 書. 東北大学大学院医学系研究科, 2001, p. 31 


\title{
Investigation of the Relationship Between Mammary Gland Doses and Image Quality of Screening Mammography in Oita
}

\author{
Tomomi Fusatsune ${ }^{1)}$, Nobuyuki Fujiwara ${ }^{2)}$, Michiaki Kai ${ }^{3)}$, Tomoko Kusama ${ }^{3)}$
}

Oita Area Health Support Center ${ }^{1}$

Oita Red Cross Hospital ${ }^{2)}$

Oita University of Nursing and Health Sciences ${ }^{3)}$

We investigated the current status of screening mammography in Oita and then examined the relationship between mammary gland dose and image quality using a RMI 156 phantom. There was a marked difference of mammary gland dose by a factor of 4.25 among facilities. This difference in dose may be due to differences in the mammography detection system and ages of the women examined. For the film-screen detection system, the image quality increased with increasing dose, whereas this was not the case for the $\mathrm{CR}$ system. Our findings suggest that screening mammography should be done using a highly sensitive film-screen detection system and a grid after determining the most suitable tube voltage for each facility.

Key words : screening mammography, film-screen detection system, CR, substantial mammary gland dose, RMI 156 phantom 